IZA DP No. 5105

Teams Make You Smarter:

Learning and Knowledge Transfer in Auctions and Markets by Teams and Individuals

Boris Maciejovsky

Matthias Sutter

David V. Budescu

Patrick Bernau

August 2010 


\title{
Teams Make You Smarter: Learning and Knowledge Transfer in Auctions and Markets by Teams and Individuals
}

\author{
Boris Maciejovsky \\ Imperial College London \\ Matthias Sutter \\ University of Innsbruck, University of Gothenburg and IZA \\ David V. Budescu \\ Fordham University \\ Patrick Bernau \\ University of Cologne and University of Innsbruck
}

\author{
Discussion Paper No. 5105 \\ August 2010
}

\author{
IZA \\ P.O. Box 7240 \\ 53072 Bonn \\ Germany \\ Phone: $+49-228-3894-0$ \\ Fax: +49-228-3894-180 \\ E-mail: iza@iza.org
}

Any opinions expressed here are those of the author(s) and not those of IZA. Research published in this series may include views on policy, but the institute itself takes no institutional policy positions.

The Institute for the Study of Labor (IZA) in Bonn is a local and virtual international research center and a place of communication between science, politics and business. IZA is an independent nonprofit organization supported by Deutsche Post Foundation. The center is associated with the University of Bonn and offers a stimulating research environment through its international network, workshops and conferences, data service, project support, research visits and doctoral program. IZA engages in (i) original and internationally competitive research in all fields of labor economics, (ii) development of policy concepts, and (iii) dissemination of research results and concepts to the interested public.

IZA Discussion Papers often represent preliminary work and are circulated to encourage discussion. Citation of such a paper should account for its provisional character. A revised version may be available directly from the author. 
IZA Discussion Paper No. 5105

August 2010

\section{ABSTRACT \\ Teams Make You Smarter: \\ Learning and Knowledge Transfer in Auctions and Markets by Teams and Individuals}

We study the impact of team decision making on market behavior and its consequences for subsequent individual performance in the Wason selection task, the single-most studied reasoning task. We reformulated the task in terms of "assets" in a market context. Teams of traders learn the task's solution faster than individuals and achieve this with weaker, less specific, performance feedback. Some teams even perform better than the best individuals. The experience of team decision-making in the market also creates positive knowledge spillovers for post-market individual performance in solving new Wason tasks, implying that team experiences enhance individual problem-solving skills.

JEL Classification: C91, C92, D03

Keywords: Wason selection task, auctions, markets, team decisions, rationality

Corresponding author:

Matthias Sutter

Department of Public Finance

University of Innsbruck

Universitaetsstrasse 15

A-6020 Innsbruck

Austria

E-mail: matthias.sutter@uibk.ac.at 


\section{$\underline{\text { Introduction }}$}

Many important decisions that, in principle, could be made by individuals are routinely made by teams. These include strategic decisions (e.g., boards of directors deciding on how much to invest in R\&D, which products to launch, and in which markets to compete), allocation decisions (e.g., committees deciding on budgetary allocations), merit-based forecasting decisions (e.g., scientific panels deciding which research proposals to fund and editorial boards deciding which books to publish), intellective decisions (e.g., committees solving complex problems) and judgmental decisions (e.g., juries selecting winners of musical, literary, sport, and beauty contests).

Most of these decisions are made by teams which are transient and temporary, being assembled by an external coordinator/supervisor or congregate spontaneously and voluntarily for a short duration, ranging from a few days (jury in a trial or a musical contest) to a few years (scientific review boards or directors of a company). These teams perform their duty and then disperse. Members are frequently selected based on their qualifications, experience or expertise, and often continue to make similar decisions as individuals when their service on the team is concluded. While there is a considerable amount of research comparing the nature and quality of the decisions made by individuals and teams, there is practically no work on the effect of being on a team on subsequent individual decisions.

In this paper we provide a first step to fill this gap. We study a logical reasoning problem that (a) is hard to solve, leaving plenty of learning opportunity; (b) is general, allowing us to test for knowledge transfers from team decision making on subsequent individual performance; (c) can be embedded in the context of auctions/markets that offer unambiguous and identical opportunities and incentives to 
all (teams and individuals), without (d) creating intra-group conflict. Our results indicate that teams (1) learn faster the solution to a reasoning problem than individuals; (2) need less specific (and weaker) performance feedback in doing so; (3) might even perform at a higher level than the best individuals, and (4) have significant spillover effects on post-market individual performance in the same task, such that individuals who have been members of a team on the market - rather than having traded on their own - are better able to solve similar reasoning tasks.

\section{$\underline{\text { Related literature }}$}

Previous research indicates that, in general, teams perform better than individuals (Tindale, Kameda \& Hinsz, 2003). ${ }^{1}$ For instance, teams are better in solving intellective tasks (e.g., Laughlin, 1980) and are better calibrated in assessing their knowledge (Allwood, \& Granhag, 1996). Teams have also been shown to play more strategically in signaling games (Cooper \& Kagel, 2005), demonstrate higher levels of strategic sophistication in normal-form games (Sutter, Czermak \& Feri, 2010), and coordinate more efficiently than individuals in coordination games (Feri, Irlenbusch \& Sutter, forthcoming). Teams are more competitive and less likely to collude (Bornstein, Kugler, Budescu \& Selten, 2008). Their behavior approaches the game-theoretic equilibrium more closely than individuals in the ultimatum game (Robert \& Carnevale, 1997; Bornstein \& Yaniv, 1998), the centipede game (Bornstein, Kugler \& Ziegelmeyer, 2004), the trust game (Kugler, Kocher, Sutter \& Bornstein, 2007), the beauty-contest game (Kocher \& Sutter, 2005), the dictator game

\footnotetext{
${ }^{1}$ There are, however, limitations to this general pattern (see, for instance, Barber \& Odean, 2000; Levine \& Moreland, 1998).
} 
(Luhan, Kocher \& Sutter, 2009), and in common pool dilemmas (Gillet, Schram \& Sonnemans, 2009).

The superiority of teams - relative to individuals - has been attributed to the "truth-wins" norm, suggesting that teams perform at the level of the best of an equal number of individuals (Laughlin \& Ellis, 1986). Successful teams engage in active discussions, allowing team members to put themselves in the shoes of their opponent (Cooper \& Kagel, 2005). These discussions allow team members to identify erroneous reasoning, reject incorrect solutions, and stimulate a more thoughtful engagement with the task at hand (Davis, 1992).

Given that, everything else being equal, teams perform better than individuals, we seek to test whether this superiority (like team membership) is transient and shortlived, or has longer-term consequences and carries over to post-interaction individual behavior. To put differently, we seek to establish that tackling a task as part of a team causes people to analyze it better and learn to solve it more effectively, allowing us to quantify the "benefits of team membership" for individual decision-making.

\section{The Present Studies}

We report the results of three studies designed to address these questions. In study 1 we seek to determine whether teams learn the solution to a reasoning problem faster than individuals in competitive auctions. In study 2 we test whether members of teams transfer their acquired knowledge more successfully to a set of new problems that need to be solved individually. Finally, in study 3 we test whether teams require weaker and less specific performance feedback to achieve these outcomes. 
All three studies have a common structure consisting of three independent stages. In the first stage, participants attempted to solve a version of the Wason selection task individually (see Table 1 and the next section for details). In the second stage participants submitted bids for potential solutions in combinatorial auctions (Studies 1 and 2) or traded solutions in double auctions (Study 3). Participants either interacted individually with three other individuals or were part of two-person teams that interacted with three other two-person teams. In the third stage, participants were asked to solve new versions of the Wason selection tasks individually (Table 1).

Next we describe the Wason selection task in more detail and explain the auction mechanism that was used in Study 1 and 2. The market mechanism used in Study 3 will be introduced in the methods section of Study 3.

\section{$\underline{\text { The Wason Selection Task }}$}

The task was originally designed to test whether individuals employ the rules of formal logic, when testing conditional statements of the form "if $p$, then $q$ " (Wason, 1966). In the standard problem, individuals are shown four cards. The cards have a letter on one side and a number on the other side. The participants' task is to verify the conditional rule "if there is a vowel $(p)$ on one side, then there is an even number $(q)$ on the other side" by identifying the minimal number of cards that must be flipped to fully test whether the rule is true or false. The cards shown are: $\mathrm{E}(p), \mathrm{K}$ (not-p), $2(q)$, and 7 (not-q). Formal logic analysis requires checking (a) the truthful implication of the rule by flipping the card E $(p)$ and (b) the potential falsification of the rule by flipping the card 7 (not-q). 
Typically, only around $10 \%$ of the participants solve the problem correctly (Griggs \& Cox, 1983). Most participants select card E (p). Many choose only this card and others select the incorrect combination of cards E (p) and $2(q)$. These findings have been replicated in numerous studies, rendering the task "the single most investigated problem in the psychology of reasoning" (Evans \& Over, 1996, p. 356).

\section{$\underline{\text { The Auction Mechanism (Study } 1 \text { and 2) }}$}

The purpose of the auction was to study whether participants can learn the correct solution to the Wason selection problem in an interactive, yet competitive setting. Participants were told that each card has a color on one side and a geometric figure on the other side. The four cards shown in the instructions were: red $(p)$, black (not-p), triangle $(q)$, and rectangle (not- $q)$. For the remainder of the article, we refer to the $\mathrm{p}$ card as Card I, the not- $p$ card as Card II, the $q$ card as Card III, and the not- $q$ card as Card IV. Participants were instructed to test the rule "If the card is red $(p)$ on one side, then there is a triangle $(q)$ on the other side" (see Table 1).

We used a combinatorial auction, allowing participants to submit buying offers (bids) for each of the 15 possible card combinations (see Figure 1 for a schematic screenshot of the auction and a complete listing of the card combinations). This procedure - in the context of the Wason selection task - was first used by Maciejovsky and Budescu (2007).

At the beginning of each trial, participants were endowed with 500 ECU (Experimental Currency Units) which were equivalent to $€ 5$ (\$6.75 at the time of the study). A total of 16 cards (four Cards I, four Cards II, four Cards III, and four Cards IV) were auctioned on each trial. During each trial, participants could submit bids for 
any card combination, as long as they had enough cash holdings. At the end of each trial, the winners of the auction were determined by a computer program implementing an algorithm designed to maximize the auctioneer's (experimenter's) revenue (i.e., the bids before paying dividends). The algorithm used an exhaustive enumeration of card partitions (for a brief discussion of a similar problem see Sandholm, 2002, or Pekeč \& Rothkopf, 2003).

After each trial, participants (teams or individuals) were awarded dividends of 200 ECU per correct pair of cards (I and IV), regardless of which other cards they held. (Teams' payoffs were doubled and split equally between the two members.) Dividends were paid out at the end of the experiment and, hence, could not be used to increase one's cash endowment of subsequent trials. Participants were not allowed to convert their ECU holdings to actual cash at the end of the experiment. We introduced this restriction to induce participants to acquire cards, rather than saving up their cash holdings. Finally, to keep the auction mechanism simple, we did not allow participants to buy cards on credit.

The participants in our studies were either individuals or two-person teams. More precisely, each auction consisted of four individual bidders or four two-person teams. Individuals/Teams were randomly assigned the role of participant/team A, B, C or D. Each experimental session consisted of multiple auction trials (30 in Study 1 and 10 in Study 2), and each trial lasted 60 seconds.

The specifics of the auction (e.g., performance feedback, payment selection) as well as the market mechanism for Study 3 will be explained together with the experimental design and procedure of the various studies in the following sections. 
Study 1: Do Teams Learn Faster Than Individuals in Combinatorial Auctions?

Participants: One hundred twenty undergraduate students (42.5\% male) from the University of Jena, aged 19 to 36 years $(M=23.24, S D=2.92)$, participated in the study.

Experimental Design and Procedure: We contrasted learning, and subsequent knowledge transfer, in 10 markets consisting of four individual bidders each $(n=40)$, and in 10 markets consisting of four two-person teams $(n=80)$ each. Subsequently, we refer to the two conditions as the INDIVIDUAL and the TEAM condition, respectively.

In every experimental session we had either 16 or 20 participants. In Stage I, participants were asked to solve one Wason selection task (first problem of Table 1) individually. Correct choices were rewarded with $€ 4$ (\$5.40), but feedback was presented only at the end of the experimental session.

In Stage II, participants were randomly assigned to groups of four in the INDIVIDUAL condition and to groups of eight in the TEAM condition. In the latter, participants were randomly split into four two-person teams, and were given time to discuss the problem prior to market opening. During the market phase, teams were requested to bid on cards in the 30 consecutive one-minute auctions (identical to the INDIVIDUAL condition). Payoff feedback about dividend earnings was provided privately to individual participants and teams after each trial.

In Stage III, participants were asked to solve eight Wason problems individually (for a complete listing see Table 1). The location of the solution cards was varied across the problems (meaning that in some problems the solution was to flip cards I and IV, in others to flip cards II and IV, I and III, etc.). This task tests for 
general knowledge transfers, because participants need to fully understand the solution concept of the problem to consistently identify the correct card combinations.

At the conclusion of a session, participants were paid their combined earnings from Stage I, three trials from Stage II (one randomly drawn auction from each block of 10 auctions: 1-10, 11-20, 21-30), and one randomly chosen problem from Stage III. In addition, individuals received €2.50 (\$3.38) for showing up. Participants in the TEAM condition received a show-up fee of $€ 4.00(\$ 5.40){ }^{2}$ Sessions lasted about 120 minutes and participants earned, on average, $€ 8.06(\$ 10.88$, $\mathrm{SDs}=€ 3.67 / \$ 4.95)$.

\section{$\underline{\text { Results }}$}

Stage I: The average rate of correct solutions was $20.0 \%$. The solution rates of subjects who were subsequently assigned to the INDIVIDUAL and TEAM conditions were $22.5 \%$ and $18.75 \%$, and did not differ significantly.

Stage II: To study whether participants learned to bid for the correct cards, we computed the proportion of bids on the correct solution $\left(B_{C}^{i, t}\right)$ out of the total amount of submitted bids $\left(500-\right.$ cash $\left.^{i, t}\right)$ for each participant/team (i) on each auction trial ( $t$ ). Bids on the correct solution were defined as bids for the combination of Cards I and IV, as well as bids for those two individual cards, when placed at the same time and for the same number of cards:

\footnotetext{
${ }^{2}$ The difference in show-up fees reflects the fact that the laboratory for team decisions was located further away from the university.
} 
$B_{C}^{i, t}= \begin{cases}\frac{B_{I, I V}^{i, t}+B_{s g l}^{i, t}}{500-\operatorname{cash}^{i, t}} & \text { if } \operatorname{cash}^{i, t}<500 \\ 0 & \text { otherwise }\end{cases}$

with

$B_{s g l}^{i, t}=n\left(B_{I}^{i, t}+B_{I V}^{i, t}\right)$ where $n=\min \left(n_{I}^{i, t}, n_{I V}^{i, t}\right)$

Bids are denoted by $B$, subscripts indicate card types (I, II, III, or IV), $n$ denotes the number of bids, and superscripts denote participants/teams ( $i$ ) and trials ( $t$ ). Note that our definition of bids on the correct solution is conservative and represents a lower bound of the target quantity. Although participants received dividends for card combinations that included redundant cards in addition to the solution (e.g., I, II, and IV), our definition of learning requires participants to identify the solution cards precisely.

Since bidding in the auction is a function of all the bidders in a group, the unit of statistical analysis is the auction rather than the individual bidder or the team. The proportion of bids on the correct solution was aggregated across the four individuals/teams in each auction. Figure 2 shows the proportion of bids that was placed on the correct solutions as a function of experimental condition and trial. We observe a monotonic increase of bids on the correct solution across auctions for both experimental conditions, suggesting that participants learn the correct solution.

We averaged the bids across auction blocks of 5 trials (block 1: trials 1-5, block 2: trials $6-10, \ldots$, block 6: trials $26-30$ ) and subjected them to a 2 -way mixed ANOVA with the between-subjects factor decision unit (INDIVIDUAL vs. TEAM) and the within-subjects factor auction block $(1-6)$. The results show significant main effects for decision unit, $\mathrm{F}(1,18)=5.64, \mathrm{p}<.05, \eta^{2}=.24$, and auction block, $\mathrm{F}(5$, $14)=6.16, p<.05, \eta^{2}=.69$, and no interaction effect. 
Stage III: Overall, subjects solved, on average, $56.7 \%$ of the tasks correctly. To isolate the net learning effect, we consider only those participants who failed to solve the Wason task in Stage I. We compared the corresponding solution rates of those participants who bid individually with those who bid as part of teams in Stage II. The results of a Mann-Whitney test indicate that solution rates do not differ significantly between these groups $(\mathrm{z}=1.03, \mathrm{p}>.05)$, suggesting that there was no advantage to individuals bidding in teams $(\mathrm{M}=51.54 \%)$ over bidding alone $(42.74 \%)$ in terms of knowledge transfer.

\section{$\underline{\text { Discussion }}$}

Study 1 demonstrates that in the context of combinatorial auctions considerable learning takes place and it is transferred successfully to post-auction behavior. In terms of our main hypothesis we found that teams learned the solution to the Wason selection task much faster than individuals, but members of teams were not necessarily more successful in transferring their knowledge to a set of new reasoning problems in Stage III. This latter result might be due to the length of bidding: The learning advantage of teams, evinced by the proportion of correct bids, diminishes across the 30 auction trials with respect to the individual auctions (see Figure 2). This means that at the beginning of Stage III subjects both from the INDIVIDUAL and the TEAM condition achieve similar levels of learning. As a consequence, we do not observe differences in the transfer of knowledge.

To test this explanation, we investigate next whether teams are superior to individuals in terms of transferring their knowledge to new problems when the learning phase is much shorter -10 auctions, instead of 30 . 
Study 2: Do Teams Transfer Their Knowledge More Successfully than Individuals in Combinatorial Auctions When Less Time for Learning is Available?

Participants: One hundred twenty undergraduate students (45\% male) from the University of Jena, aged 18 to 34 years $(\mathrm{M}=22.56, \mathrm{SD}=2.82)$, participated in the study. None of them had participated in Study 1.

Experimental Design and Procedure: In every experimental session we had either 16 or 24 participants. Sessions lasted about 95 minutes and participants earned, on average, $€ 6.75$ (\$9.11, SDs=€3.17 / \$4.28).

Study 2 is an exact replication of Study 1 with two changes: We reduced the number of auction trials from 30 to 10 , and we determined payoffs for Stage II by randomly selecting only one of the 10 trials (instead of paying three out of 30 trials as in Study 1 - where we also selected one trial from the first ten trials, though).

\section{$\underline{\text { Results }}$}

Stage I: The average rate of correct solutions was $28.3 \%$. The solution rates of subjects who were subsequently assigned to the INDIVIDUAL and TEAM conditions were $27.5 \%$ and $28.75 \%$, and did not differ significantly.

Stage II: Figure 3 shows the proportion of bids on the correct solution across trials as a function of experimental condition. We analyzed the proportion of bids on the correct solution in a 2-way mixed ANOVA with the between-subjects factor decision unit (INDIVIDUAL vs. TEAM) and the within-subjects factor auction block (auction trials 1-5 vs. auction trials 6-10). The results show significant main effects for decision unit, $\mathrm{F}(1,18)=4.54, \mathrm{p}<.05, \eta^{2}=.20$, and auction block, $\mathrm{F}(1,18)=10.55$, $\mathrm{p}<.05, \eta^{2}=.37$, but no interaction effect. 
Stage III: Overall, participants solved, on average, $56.98 \%$ of the transfer problems. We compared the solution rates of those participants who failed to solve the Wason task in Stage I and bid individually or as part of teams in Stage II. Individuals, who participated as part of teams, solved a significantly higher percentage of transfer problems $(56.36 \%)$ than individuals who participated in individual auctions $(27.59 \%)$ (Mann-Whitney test $\mathrm{z}=2.76, \mathrm{p}<.05$ ).

\section{$\underline{\text { Discussion }}$}

Study 2 replicates all the results of Study 1 regarding the superior learning of teams, and demonstrates that individuals who bid as part of teams were more successful in transferring their acquired knowledge to a set of new Wason problems than the individual bidders when the learning period was relatively short.

In Study 3 we extend these findings by testing whether teams can achieve similar results with weaker and less specific performance feedback. To test this hypothesis we use a market mechanism - a continuous double auction - that makes learning more difficult in comparison to the combinatorial auctions. We also manipulate the quality of earnings' feedback between successive trading periods. The distinctive characteristics of the double auction markets that make learning more difficult are:

- $\quad$ The market is "thin" (only four traders per auction), which leads to noisy trading prices.

- $\quad$ Participants engage in buying and selling activities at the same time, making it harder to properly track trading activity. 
- Individual traders cannot be identified (and imitated). Only aggregate (and anonymous) market behavior is observed.

- The traders' motivation is ambiguous since this mechanism provides an incentive to acquire incorrect cards, as long as traders believe that other participants may wish to buy these cards later at a premium.

- Cards are traded individually. Since the solution requires traders to hold two cards to receive dividends, they expose themselves to execution risk (holding one card by itself is worthless without having the other).

We hypothesize that teams would achieve higher levels of learning and would be more successful at transferring their knowledge than individuals, despite the noisy market mechanism. Hence, study 3 provides a stress test for the robustness of our findings.

\section{Study 3: Do Teams Require Less Specific Performance Feedback Than Individuals?}

Participants: Two hundred forty undergraduate students $(41.67 \%$ male) from the University of London, aged 19 to 36 years $(\mathrm{M}=22.92, \mathrm{SD}=2.68)$, participated in the study. Sessions lasted about 100 minutes and participants earned, on average, $£ 13.34(\$ 19.89, \mathrm{SDs}=£ 4.58 / \$ 6.83$,$) .$

Experimental Design and Procedure: We contrasted learning, and subsequent knowledge transfers, in a 2 (decision unit: INDIVIDUAL vs. TEAM) by 2 (performance feedback: strong vs. weak) between-subjects design. We had 10 markets in each of the four cells, with $n=40$ participants in each of the two individual conditions, and 40 dyads $(n=80)$ in each of the two team conditions. 
In Stage I, participants were asked to solve the Wason selection task (first problem of Table 1) individually. Correct choices were rewarded with $£ 2$ (\$2.98), but feedback was presented only at the end of the experimental session.

In Stage II, participants were randomly assigned to experimental conditions and traded the cards of the second Wason selection task (second problem of Table 1) in computerized double auctions (implemented with the software z-Tree, Fischbacher, 2007). This procedure was first used in this context by Budescu and Maciejovsky (2005). Trading only started when participants had solved correctly all the items of a short quiz, designed to check understanding of the instructions.

Each market consisted of 12 trading periods during which participants could buy and / or sell the four cards simultaneously in continuous anonymous double auctions (see Figure 4 for a schematic screenshot of the auction). Each market consisted of four participants (individuals or two-person teams). At the beginning of each period, participants were endowed with $120 \mathrm{ECU}$ (exchange rate: $100 \mathrm{ECU}=$ $£ 10$ ) and with four cards of the same type (i.e., Card I, II, III, or IV). To induce trading, only one participant in each market was endowed with a given card. The card assignment was determined randomly in each period.

Trading periods lasted for 180 seconds. Participants could submit bids and / or asks; they could also accept standing offers (bids and asks) by other market participants. Only improving offers, i.e., higher bids and lower asks, were allowed. Participants were shown lists of concluded contracts for each card (in chronological order) and were informed about the remaining trading time and the current period number. Participants were not granted any credit and were not allowed to sell cards short, i.e., they were only allowed to make bids up to their cash holdings and submit asks for cards they actually owned. 
If participants held the correct cards at the end of an auction period, they received dividends of $80 \mathrm{ECU}$ for each complete set of solution cards. We varied the quality of the performance feedback that participants received at the end of each trading period (see Figure 5 for a schematic screenshot of the information provided). Participants in the strong-performance feedback condition were informed about the dividends associated with each of the four cards separately (see Figure 5a). In contrast, participants in the weak-performance feedback condition were only shown the aggregate amount of dividends, without a direct link to the individual card holdings (see Figure 5b).

At the end of the auction, one period was randomly selected and participants obtained their cash holdings and dividend payments for that particular period at the end of the experimental sessions.

In Stage III, participants were asked to solve eight new Wason problems (identical to Study 1 and 2) individually. One of the eight problems was randomly selected and participants received £2, if they solved it correctly, on top of their earnings from Stage I and II. If participants’ total earnings fell short of $£ 4$ (\$5.96), they received this amount.

$\underline{\text { Results }}$

Stage I: The average solution rate was $7.9 \%$ There was no significant difference between subjects who were later assigned to the INDIVIDUAL (8.8\%) and TEAM condition $(7.5 \%)$.

Stage II: Figure 6 shows the average trading prices for the four cards across periods as a function of interaction and feedback. Prices for correct (incorrect) cards 
were generally higher (lower) for TEAM (INDIVIDUAL) traders and with strong (weak) performance feedback. To study whether participants learned to identify the correct cards, we aggregated the trading prices across periods for each of the four cards as a function of experimental condition and the 10 market cohorts. We then computed the average trading price for the correct cards and subtracted the average trading price for the incorrect cards. This measure was subjected to a 2-way ANOVA with the between-subjects factors decision unit (INDIVIDUAL vs. TEAM) and performance feedback (strong vs. weak). The results show significant main effects for decision unit $\left(\mathrm{F}(1,35)=87.39, \mathrm{p}<.05, \eta^{2}=.71\right)$ and performance feedback $(\mathrm{F}(1$, $35)=10.58, \mathrm{p}<.05, \eta^{2}=.23$ ), but no interaction effect (see Table 2 ).

Stage III: Overall, participants solved, on average, $42.71 \%$ of the transfer problems. Isolating the learning effect by considering only those participants who failed to solve the Wason task in Stage I, we compared the corresponding solution rates of those participants who bid individually with those who bid as part of teams. Individuals, who participated as part of teams, solved a significantly higher percentage of transfer problems (43.67\%) than individuals who participated in individual auctions (27.23\%) (Mann-Whitney test $\mathrm{z}=2.25, \mathrm{p}<.05)$.

To investigate the combined effects of decision unit and performance feedback, we computed for each individual the percentage of correct choices across the eight transfer problems and subjected this measure to a 2-way ANOVA with the between-subjects factors decision unit (INDIVIDUAL vs. TEAM) and performance feedback (strong vs. weak). The results show a significant main effect for decision unit $\left(\mathrm{F}(1,236)=5.90, \mathrm{p}<.05, \eta^{2}=.02\right)$, but neither a significant effect for performance feedback nor an interaction effect. 


\section{$\underline{\text { Discussion }}$}

Study 3 shows that teams were able to learn the correct solution to the Wason selection problem in competitive markets with less specific (and weaker) performance feedback than individuals. To put our results in perspective note that the panels pertaining to the cards that make up the correct solution in Figure 6 show that the trading prices of teams with weak feedback are indistinguishable from the prices of individuals with strong feedback. Members of teams were also more successful in transferring their acquired knowledge to new problems in Stage III.

Synopsis: What Accounts for the Superior Learning, and Transfer of Skills, in Teams?

A straightforward explanation of our findings is that teams perform at the level of their best members. According to such a "truth wins" norm, a knowledgeable minority of group members can convince the majority by demonstrating the correct solution (Laughlin, 1980). This effect would shift the level of learning and knowledge transfers upward in teams (relative to individuals). To test this explanation we compared learning rates (inferred from the proportion of bids on the correct solutions in Studies 1 and 2) between the best individual in each cohort (aggregated across all trials) to the average team in each cohort (aggregated across trials). We did not find statistically significant differences between these distributions for Studies 1 and 2, meaning that the average team performs as good as the best individual, but not better.

However, a similar analysis for Study 3 shows that the average team performance is significantly better than the best individual traders. This analysis is based on the contrast between submitted bids for Cards III and IV. All our prior analyses suggest that the crucial indication of identifying the correct solution in the Wason selection task hinges on the insight that Card IV is essential to test it, while the 
incorrect Card III seems the initially most likely candidate for a majority of subjects.

Consequently, we calculated for each individual/team the difference in bids submitted for Card IV and Card III, aggregated this measure across periods and compared the best individuals (as defined by the maximum difference between the bids submitted for Card IV and Card III) to the average team in each cohort as a function of performance feedback. The results show significant main effects for decision unit $\left(\mathrm{F}(1,36)=7.59, \mathrm{p}<.05, \eta^{2}=.17\right)$ and performance feedback $(\mathrm{F}(1$, 36) $=5.90, p<.05, \eta^{2}=.14$ ), but no interaction effect (see Table 3 ).

Another way of confirming the superiority of teams is to compare team and individual performance on markets where none of the participants solved correctly the Wason problem in Stage I. There were a total of 24 such markets (10 in the TEAM condition and 14 in the INDIVIDUAL condition). We ran the same ANOVA of the difference in bids for Card IV and Card III on this restricted sample and obtained similar significant effects for decision unit $\left(\mathrm{F}(1,20)=28.94, \mathrm{p}<.05, \eta^{2}=.59\right)$ and feedback $\left(\mathrm{F}(1,20)=6.25, \mathrm{p}<.05, \eta^{2}=.24\right)$, confirming that teams do better than individuals and strong feedback is more effective than weak feedback.

These results provide evidence that teams are capable of performing at a higher level than the best individual traders! A reasonable explanation is that team members challenge each other's solutions, thereby inducing deeper, and more critical, levels of thinking and analysis, which help in identifying the correct solution. The fact that we observed this finding in Study 3 - the most difficult market mechanism for learning - and not in Studies 1 and 2, might be related to this very point. We speculate that individuals might be more motivated - and hence more likely to challenge each other's solutions and explanations - in more complex environments. 


\section{$\underline{\text { Conclusions }}$}

We have studied the impact of team decision making on market behavior and on subsequent individual performance in the Wason selection task, the single-most studied reasoning task. While there has been considerable research comparing the nature and quality of the decisions made by individuals and teams (see, e.g., Bornstein, Kugler \& Ziegelmeyer, 2004; Bornstein \& Yaniv, 1998; Cooper and Kagel, 2005; Feri, Irlenbusch \& Sutter, forthcoming; Kocher and Sutter, 2005), there has been no work on the effects of being on a team on subsequent individual decisions and problem solving skills.

Our results on the differences between individuals and teams are largely in line with earlier studies, as they confirm that teams tend to perform better than individuals: Teams of traders learn the correct solution to the Wason task faster than individuals and achieve this with less specific performance feedback. Teams can even beat a very high threshold - the truth-wins norm - with less precise feedback. This seems to be driven by the teams' tendency to analyze more carefully the more complex problems. Although we do not have direct evidence, we suspect that some of the processes that were shown in other contexts to affect individual decision makers such as susceptibility to compelling and persuasive arguments (e.g., Bishop \& Myers, 1974; Burnstein, 1982), or sensitivity to being evaluated by others (e.g., Curley, Yates \& Abrams, 1986) play a role in this.

The main contribution of our paper relates to the degree of knowledge transfer from team decision making to subsequent individual tasks. Recall that all participants had to make a similar number of decisions - either individually or as members of twoperson teams - in the auctions and markets run in Stage II of our three studies. We have found that the decision unit (acting individually or as a team) in Stage II has a 
tremendous impact on the participants' performance in Stage III where they had to solve individually eight new Wason selection problems. In particular, having been a member of a team in Stage II led to higher solution rates in Stage III, and the difference to participants who had acted individually in Stage II was significant in studies 2 and 3 where the opportunities for learning were shorter and feedback was less precise.

Table 4 summarizes the rate of transfer for individuals and groups across all 3 studies (Stage III). We classify the transfer scores into 3 categories: 0-1 suggests no (or almost no) transfer, while 7-8 indicates perfect (or almost perfect) transfer. The other category (2-6 solutions) suggests mixed results, but only a small minority (13\%) of the subjects falls in this group. The overall distribution is almost symmetric with, essentially, equal numbers of people in the no transfer and perfect transfer categories, but note that the pattern is different in the two groups: The modal classification for INDIVIDUAL is no transfer (54\%) and for TEAMS it is perfect transfer (48\%), and the two distributions are significantly different $\left(\chi_{2 d f}^{2}=9.89 ; p<0.01\right)$. Thus, we can safely conclude that the experience of team decision making increases individual problem solving skills. An important topic for future research is to determine the boundary conditions of this effect. More specifically, how stable and persistent is the effect over time and to what degree does it generalize to other problems.

Our key finding of positive knowledge spillovers from team decision-making to subsequent (post-interaction) individual behavior, and the associated enhanced problem-solving skills, has important managerial implications. It supports the use of teams in organizational tasks not only as a means to get better decisions, but also as a training tool to improve the skills of individuals for subsequent individual tasks, 
suggesting that team decision-making can be used as a training instrument in human resource development. 


\section{$\underline{\text { References }}$}

Allwood, C. M., \& Granhag, P. A. (1996). Realism in confidence judgments as a function of working in dyads or alone. Organizational Behavior and Human Decision Performance, 76, 277-289.

Barber, B. M., \& Odean, T. (2000). Too many cooks spoil the profits: Investment club performance. Financial Analyst Journal, 56, 17-25.

Bishop. G. D., \& Myers, D. G. (1974). Informational influences in group discussion. Organizational Behavior and Human Performance, 12, 92-104.

Bornstein, G., \& Yaniv, I. (1998). Individual and group behavior in the ultimatum game: Are groups more "rational" players? Experimental Economics, 1, 101-108.

Bornstein, G., Kugler, T., Budescu, D. V., \& Selten, R. (2008). Repeated price competition between teams. Journal of Economic Behavior and Organization, 66, 808-821.

Bornstein, G., Kugler, T., \& Ziegelmeyer, A. (2004). Individual and group decisions in the centipede game: Are groups more rational players? Journal of Experimental Social Psychology, 40, 599-605.

Budescu. D. V., \& Maciejovsky, B. (2005). The effect of monetary feedback and information spillover on cognitive errors: Evidence from competitive markets. Management Science, 51, 1829-1843.

Burnstein, E. (1982). Persuasion as argument processing. In: H. Brandstätter, J. H. Davis, \& G. Stocher-Kreichgauer (Eds.). Contemporary Problems in Group Decision-Making (pp. 103-125). New York: Academic Press.

Cooper, D. J., \& Kagel, J. H. (2005). Are two heads better than one? Team versus individual play in signaling games. American Economic Review, 95, 477-509.

Curley, S. P., Yates, J. F., \& Abrams, R. A. (1986). Psychological sources of ambiguity avoidance. Organizational. Behavior and Human Decision Processes, 38, 230-256.

Davis, J. H. (1992). Some compelling intuitions about group consensus decisions, theoretical and empirical research, and interpersonal aggregation phenomena: Selected examples, 1950-1990. Organizational Behavior and Human Decision Processes, 52, 3-38.

Evans, J. S. B. T., \& Over, D. E. (1996). Rationality in the selection task: Epistemic utility versus uncertainty reduction. Psychological Review, 103, 356-363. 
Fischbacher, U. (2007). Z-tree. Zurich toolbox for readymade economic experiments. Experimental Economics, 10, 171-178.

Feri, F., Irlenbusch, B., \& Sutter, M. (forthcoming). Efficiency gains from team-based coordination: Large-scale experimental evidence. American Economic Review.

Gillet, J., Schram, A., \& Sonnemans, J. (2009). The tragedy of the commons revisited: The importance of group decision making. Journal of Public Economics, 93, 785797.

Griggs, R. A., \& Cox, J. R. (1983). The effects of problem content and negation on Wason's selection task. Quarterly Journal of Experimental Psychology, 35A, 519533.

Kocher, M., \& Sutter, M. (2005). The decision maker matters: Individual versus team behavior in experimental beauty-contest games. Economic Journal, 115, 200-223.

Kugler, T., Kocher, M., Sutter, M., \& Bornstein, G. (2007). Trust between individuals and groups: Groups are less trusting than individuals but just as trustworthy. Journal of Economic Psychology, 28, 646-657.

Laughlin, P. R. (1980). Social combination processes of cooperative, problem-solving groups on verbal intellective tasks. In M. Fishbein (Ed.). Progress in Social Psychology. Vol. 1. (pp. 127-155). Hillsdale, NJ: Lawrence-Erlbaum.

Laughlin, P. R., \& Ellis, A. L. (1986). Demonstrability and social combination processes on mathematical intellective tasks. Journal of Experimental Social Psychology, 22, 177-189.

Levine, J. M., \& Moreland, R. L. (1998). Small groups. In: D. T. Gilbert, S. T. Fiske, \& G. Lindzey (Eds.). Handbook of Social Psychology. Vol. 2. (pp. 415-469). Boston: McGraw-Hill.

Luhan, W., Kocher, M., \& Sutter, M. (2009). Group polarization in the team dictator game reconsidered. Experimental Economics, 12, 26-41.

Maciejovsky, B., \& Budescu, D. V. (2007). Collective induction without cooperation? Learning and knowledge transfer in cooperative groups and competitive auctions. Journal of Personality and Social Psychology, 92, 854-870.

Pekeč, A., \& Rothkopf, M. H. (2003). Combinatorial auction design. Management Science, 49, 1485-1503.

Robert, C., \& Carnevale, P. J. (1997). Group choice in ultimatum bargaining. Organizational Behavior and Human Decision Processes, 72, 256-279. 
Sandholm, T. (2002). Algorithm for optimal winner determination in combinatorial auctions. Artificial Intelligence, 135, 1-54.

Sutter, M., Czermak, S., \& Feri, F. (2010). Strategic sophistication of individuals and teams in experimental normal-form games. IZA Discussion Paper 4732.

Tindale, R. S., Kameda, T., \& Hinsz, V. B. (2003). Group decision making. In: M. A. Hogg \& J. Cooper (Eds.). The SAGE Handbook of Social Psychology (pp.381403). London, Sage.

Wason, P. C. (1966). Reasoning. In: B. Foss (Ed.). New Horizons in Psychology (pp. 135-151). Harmondsworth: Penguin Books. 
Table 1: Materials Used in Studies 1-3

\begin{tabular}{|c|c|c|c|c|}
\hline & \multicolumn{4}{|c|}{ Cards } \\
\hline Stage I: & I & II & III & IV \\
\hline $\begin{array}{l}\text { 1. If the card is blue on one side, then there is a } \\
\text { square on the other side. (I, IV) }\end{array}$ & & & & \\
\hline Stage II: & & & & \\
\hline $\begin{array}{l}\text { 2. If the card is red on one side, then there is a } \\
\text { triangle on the other side. (I, IV) }\end{array}$ & & & $\angle$ & \\
\hline Stage III: & & & & \\
\hline $\begin{array}{l}\text { 3. If the card is blue on one side, then there is a } \\
\text { square on the other side. (I, IV) }\end{array}$ & & & & \\
\hline $\begin{array}{l}\text { 4. If there is a small triangle on one side, then } \\
\text { there is a } \$ \text {-symbol on the other side. (III, IV) }\end{array}$ & $\$$ & & $£$ & $\triangle$ \\
\hline $\begin{array}{l}\text { 5. If there is a vowel on one side, then there is } \\
\text { an even number on the other side. (II, III) }\end{array}$ & K & $\mathrm{E}$ & 7 & 2 \\
\hline $\begin{array}{l}\text { 6. If there is a circle on one side, then the card } \\
\text { is yellow on the other side. (I, II) }\end{array}$ & & & $\triangle$ & \\
\hline $\begin{array}{l}\text { 7. If there is an arrow that points to right on } \\
\text { one side, then there is a large cube on the other } \\
\text { side. (II, IV) }\end{array}$ & $\hookleftarrow$ & $\Rightarrow$ & $\square$ & (1) \\
\hline $\begin{array}{l}\text { 8. If the card is grey on one side, then there is } \\
\text { an \&-symbol on the other side. (I, III) }\end{array}$ & & $\&$ & $\S$ & \\
\hline $\begin{array}{l}\text { 9. If a person gets a bonus, she must have sold } \\
\text { more than } 125 \text { units. (I, IV) }\end{array}$ & Bonus & $\begin{array}{c}> \\
125 \\
\end{array}$ & $\begin{array}{c}\text { No } \\
\text { Bonus }\end{array}$ & $\begin{array}{c}< \\
125 \\
\end{array}$ \\
\hline $\begin{array}{l}\text { 10. If a person drinks alcohol, she must be } \\
\text { older than } 21 \text { years of age. (I, IV) }\end{array}$ & Beer & Cola & $21 \mathrm{yrs}$ & $16 \mathrm{yrs}$ \\
\hline
\end{tabular}

Note: Correct card combinations are shown in parentheses. 
Table 2: Difference Between the Average Trading Price for Correct Cards and Average Trading Price for Incorrect Cards as a Function of Decision Unit and Performance Feedback (Study 3)

\section{Performance Feedback}

\begin{tabular}{l|cc}
\hline & Weak & Strong \\
\hline Decision Unit & Mean (SD) & Mean (SD) \\
\hline Individual & $4.77(7.90)$ & $10.24(6.97)$ \\
Team & $23.03(7.04)$ & $31.21(3.95)$ \\
\hline
\end{tabular}


Table 3: Difference Between Average Submitted Bids for Card IV and Card III as a Function of Decision Unit and Performance Feedback (Study 3)

Performance Feedback

\begin{tabular}{l|cc}
\hline & Weak & Strong \\
\hline Decision Unit & Mean (SD) & Mean (SD) \\
\hline Best Individual & $10.51(19.07)$ & $18.05(8.87)$ \\
Average Team & $19.28(9.19)$ & $29.98(6.14)$ \\
\hline
\end{tabular}


Table 4: Distribution (in \%) of Number of Correct Solutions in the General Transfer Task (Stage III) across Studies and Experimental Conditions

\begin{tabular}{l|ll|l}
\hline \hline Correct Solutions & Individuals & Teams & Total \\
\hline No Transfer (0-1) & $\mathbf{5 4}$ & 39 & 44 \\
$2-6$ & 13 & 13 & 13 \\
Perfect Transfer (7-8) & 33 & $\mathbf{4 8}$ & 43 \\
\hline Sample size & 160 & 320 & 480
\end{tabular}

Note: The modal category is bold face 
Figure 1: Schematic Screenshot of the Combinatorial Auction (Study 1 and 2)

\begin{tabular}{|c|c|c|c|c|c|c|c|c|c|c|c|c|}
\hline \multicolumn{10}{|c|}{ You are PARTICIPANT C } & \multirow[t]{3}{*}{ Trial 4} & \multicolumn{2}{|c|}{ Seconds 9} \\
\hline \multicolumn{5}{|c|}{ Participant A } & \multicolumn{5}{|c|}{ Participant B } & & & \\
\hline \multicolumn{5}{|c|}{ Mean Bid (Quantity) in Trial } & \multicolumn{5}{|c|}{ Mean Bid (Quantity) in Trial } & & & \\
\hline Combination & 1 & 2 & 3 & Current & Combination & 1 & 2 & 3 & Current & Combination & Price & Quantity \\
\hline 1 & - & - & $99(1)$ & - & 1 & - & - & 50 (3) & - & 1 & & \\
\hline ॥ & - & - & - & - & ॥ & $70(1)$ & - & - & - & ॥ & & \\
\hline IIII & - & - & - & - & IIII & $69(1)$ & - & $50(3)$ & - & III & & \\
\hline IV & - & - & $99(1)$ & - & Iv & $1(1)$ & - & - & - & IV & & \\
\hline 1,11 & - & - & - & - & 1,11 & - & - & - & - & 1,11 & & \\
\hline I, III & 190 (1) & - & - & - & 1, III & - & - & $199(1)$ & - & I, III & & \\
\hline $1, I V$ & - & - & 151 (2) & - & I, IV & - & - & - & - & I, IV & & \\
\hline $\mathrm{II}, \mathrm{III}$ & - & - & - & - & II, III & $180(1)$ & - & - & - & II, III & & \\
\hline II, IV & - & - & - & - & II, IV & - & - & - & - & II, IV & & \\
\hline III, IV & - & - & - & - & III, IV & - & - & - & - & III, IV & & \\
\hline I, II, III & 155 (1) & - & - & - & I, II, III & - & - & - & - & $1,11, \mathrm{III}$ & & \\
\hline I, II, IV & - & - & - & - & I, II, IV & - & - & - & - & I, II, IV & & \\
\hline I, III, IV & 155 (1) & - & - & - & I, III, IV & - & - & - & - & I, III, IV & & \\
\hline III, III, IV & - & - & - & - & II, III, IV & - & - & - & - & II, III, IV & & \\
\hline $\mathrm{I}, \mathrm{II}, \mathrm{III}, \mathrm{IV}$ & - & - & - & - & I, II, III, IV & $180(1)$ & - & - & - & I, II, III, IV & & \\
\hline \multicolumn{5}{|c|}{ Participant C } & \multicolumn{5}{|c|}{ Participant D } & \multirow{18}{*}{$\begin{array}{l}\text { Your cas } \\
\text { holdinas }\end{array}$} & & SURMIT \\
\hline & Mean Bid & Quantity) & & & & ean Bid ( & antity) in & & & & & \\
\hline Combination & 1 & 2 & 3 & Current & Combination & 2 & 3 & 4 & Current & & & \\
\hline 1 & - & $80(1)$ & - & 99 (1) & 1 & - & - & - & - & & & \\
\hline II & - & $80(1)$ & - & - & II & - & - & - & - & & & \\
\hline IIII & - & 80 (1) & - & - & III & - & - & - & - & & & \\
\hline IV & - & 80 (1) & - & - & IV & - & - & - & - & & & \\
\hline 1,11 & - & - & - & - & 1,11 & - & - & - & - & & & \\
\hline I. III & - & - & - & - & I. III & - & - & - & - & & & \\
\hline I. IV & - & - & - & - & I, IV & - & $190(1)$ & - & - & & & \\
\hline II, III & - & - & - & - & II, III & - & - & - & - & & & \\
\hline II, IV & - & - & - & - & $\mathrm{II}, \mathrm{IV}$ & - & - & - & - & & & \\
\hline III. IV & - & - & - & - & III. IV & - & - & - & - & & & \\
\hline I, II, III & - & - & - & - & I, II, III & - & - & - & - & & & \\
\hline I, II, IV & - & - & - & . & I, II, IV & - & $155(1)$ & - & - & & & \\
\hline I, III, IV & - & - & - & - & I, III, IV & - & $155(1)$ & - & - & & & \\
\hline II. III. IV & - & - & - & - & II. III. IV & - & - & - & - & & & \\
\hline I, II, III, IV & - & 180 (1) & - & - & I, II, III, IV & - & - & - & - & & & \\
\hline
\end{tabular}


Figure 2: Average Proportion of Bids on the Correct Solution (and Standard Errors) in the Individual Condition and the Team Condition across Auction Trials (Study 1)

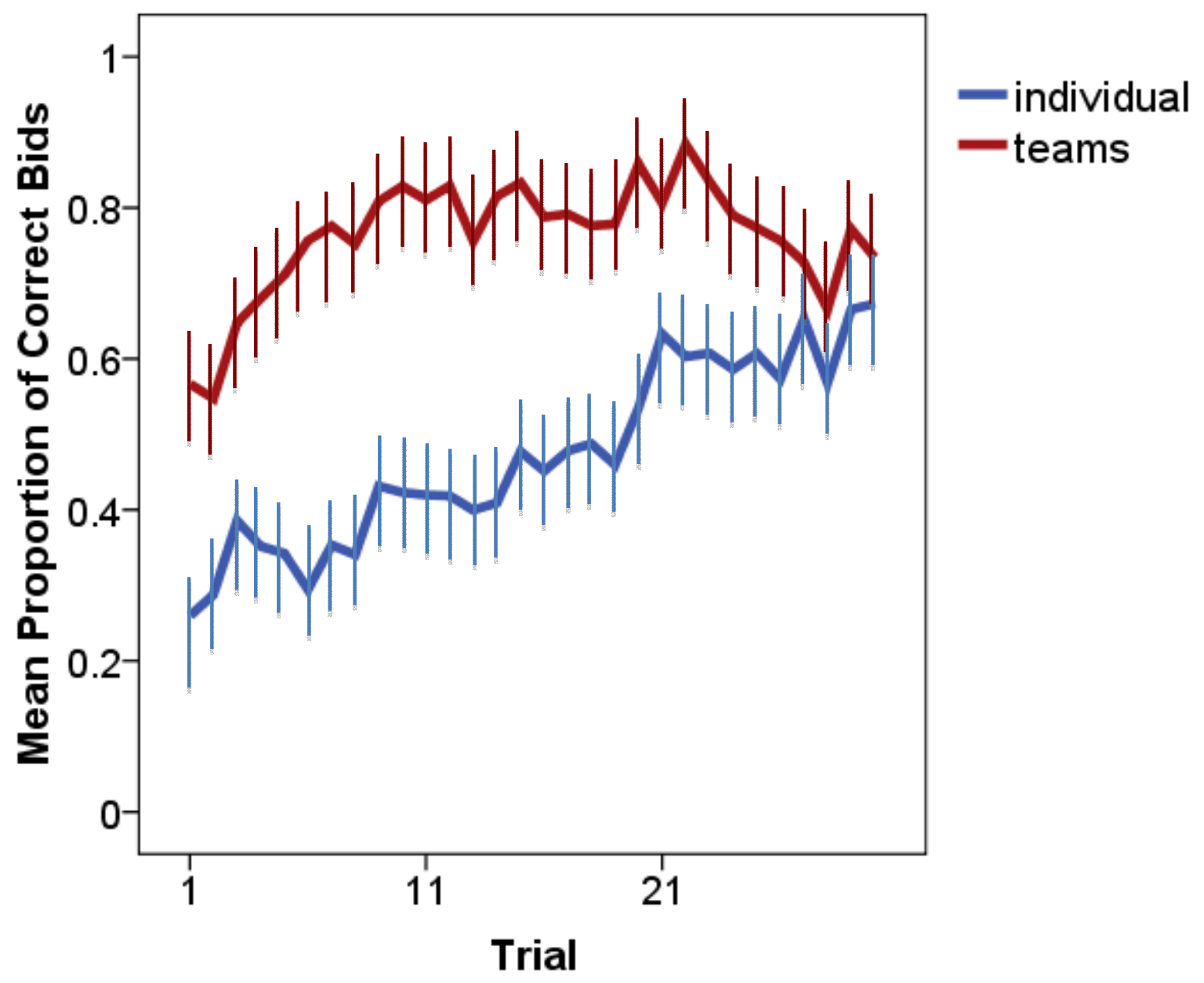


Figure 3: Average Proportion of Bids on the Correct Solution (and Standard Errors) in the Individual Condition and the Team Condition across Auction Trials (Study 2)

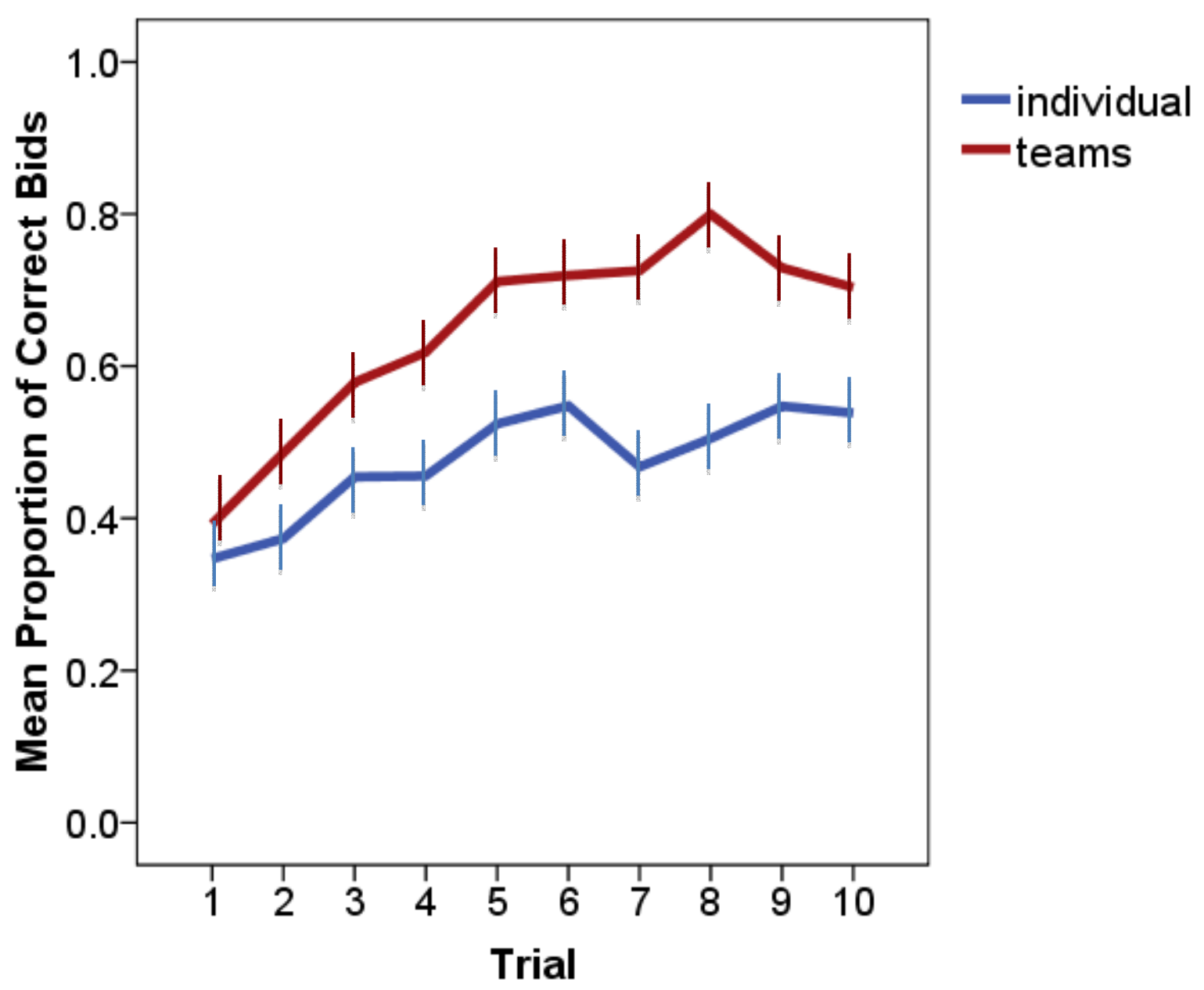


Figure 4: Schematic Screenshot of the Double Auction (Study 3)

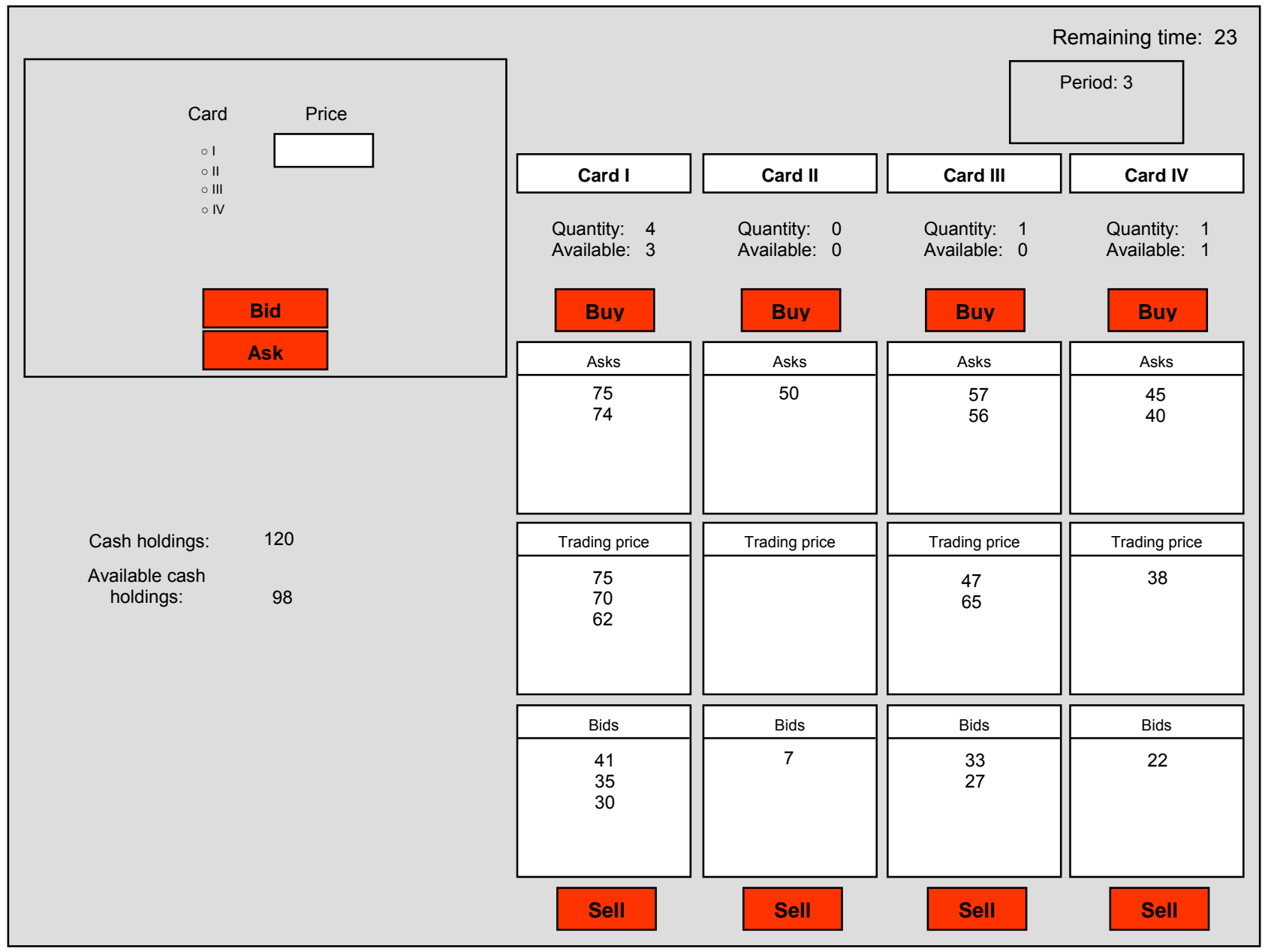


Figure 5: Schematic Screenshot of the Performance Feedback (Study 3)

At the end of this period your cash holdings are: 44 ECU

Your card holdings and dividend payments are:

\begin{tabular}{|l|l|l|}
\hline & Card Holdings & Dividends \\
\hline Card I & 2 & 40 \\
\hline Card II & 0 & 0 \\
\hline Card III & 1 & 0 \\
\hline Card IV & 1 & 40 \\
\hline
\end{tabular}

Your dividends are: 80 ECU

Your total earnings are: 124 ECU

a: Strong Performance Feedback

At the end of this period your cash holdings are: $44 \mathrm{ECU}$

Your card holdings are:

\begin{tabular}{|l|l|}
\hline & Card Holdings \\
\hline Card I & 2 \\
\hline Card II & 0 \\
\hline Card III & 1 \\
\hline Card IV & 1 \\
\hline
\end{tabular}

Your dividends are: 80 ECU

Your total earnings are: 124 ECU

b: Weak Performance Feedback 
Figure 6: Average Trading Prices for the Four Cards as a Function of Experimental Condition and Period (Study 3)
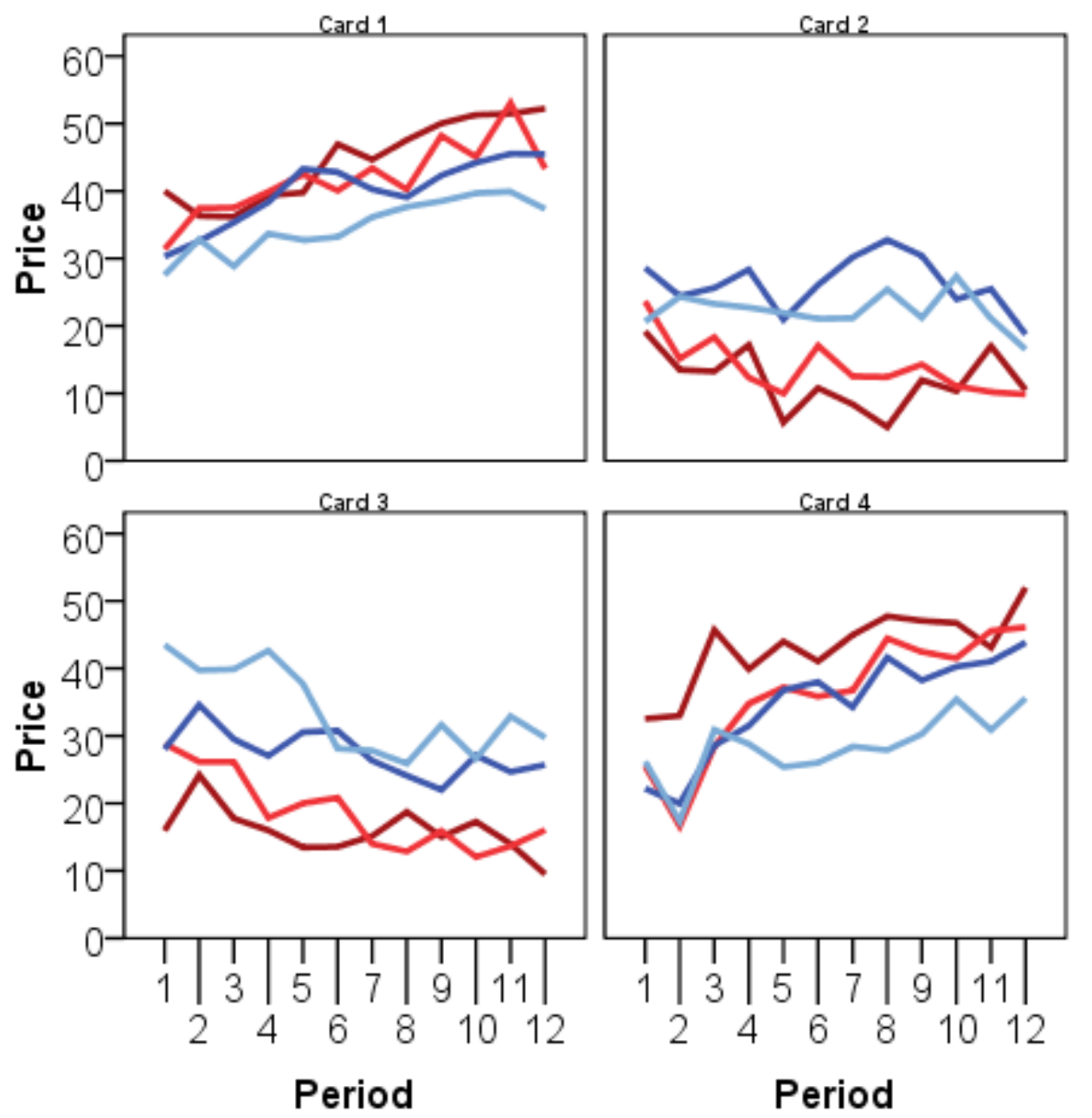

- Team - Strong

- Team - Weak

— Indiv - Strong

- Indiv - Weak

Lines show Mean

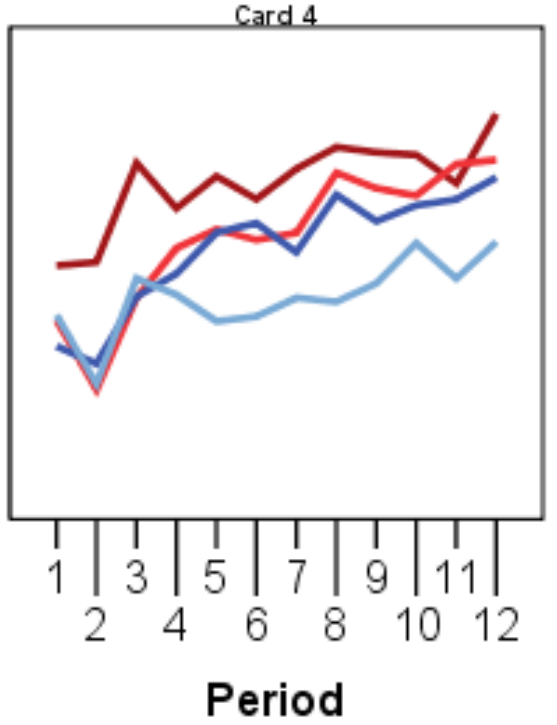

